\section{O movimento de mães contra a violência policial nas periferias brasileiras}

Recebido: 30.04 .21 Aprovado: 05.08.21

\author{
Débora Françolin Quintela (https://orcid.org/0000-0001-9663-7556), \\ Departamento de Ciência Política, Universidade de Brasília, \\ Brasília, Distrito Federal, Brasil'.
}

Resumo: 0 artigo propõe analisar o ativismo político de mães de vítimas da letalidade da ação policial nas periferias brasileiras a partir da perspectiva dos movimentos sociais. Inicia-se pela apresentação dessa forma de ação coletiva, marcada pela condição de maternidade e pela vulnerabilidade, para, então, observá-lo a partir de categorias frequentemente destacadas na teoria dos movimentos sociais. Neste empenho, são delineadas as suas principais características, destacando-se entre elas a relevância do aspecto emotivo. Dor, raiva e ultraje, tanto quanto amor, acolhimento e solidariedade são afetos fundamentais para uma compreensão aprofundada das mães em luta. A análise é baseada em entrevistas de profundidade com ativistas do movimento, na participação da pesquisadora em atos e em revisão bibliográfica. Conclui-se que estamos diante de um movimento social singular e salienta-se a imprescindibilidade de uma perspectiva atenta às emoções nesse campo de estudos, fundamental para a compreensão de um movimento como este.

Palavras-chave: Movimentos sociais. Movimentos de mães. Letalidade policial. Ativismo político. Emoções.

\section{Mothers' movement against police violence in Brazilian peripheries}

The article proposes the analysis of the political activism of women mothers of victims of police lethality in low-income suburbs of Brazil from the perspective of social movements. It begins with the presentation of this collective action, marked by the condition of motherhood and vulnerability, and then investigates it from categories frequently highlighted in the theory of social movements. In this endeavor, its main characteristics are outlined, especially the relevance of the emotional aspect. Pain, anger and outrage, as well as love, welcome and solidarity, are fundamental affects for an in-depth understanding of mothers in struggle. The analysis is based on in-depth interviews with movement activists, on the researcher's participation in political acts and on bibliographic review. It concludes that we are facing a singular social movement and outlines the importance of an attentive to emotions perspective in this field of studies, fundamental for the understanding of such a movement.

Keywords: Social movements. Mothers' movements. Police lethality. Political activism. Emotions.

\author{
I. Débora Françolin \\ Quintela é \\ doutoranda em \\ ciência política pela \\ Universidade de \\ Brasília (UnB), mestra \\ e bacharel em \\ ciência política pela \\ mesma instituição. \\ <deborafrancolin@ \\ gmail.com>
}




\section{Introdução}

1. Todos os dados apresentados neste parágrafo e no seguinte têm como fonte o Anuário Brasileiro de Segurança Pública de 2020 (Fórum Brasileiro de Segurança Pública, 2020).

2. Convencionou-se, no debate público e na grande mídia, referir-se às vítimas de armas de fogo em situações

"acidentais" - em que não havia confronto armado -, como vítimas de

"balas perdidas". Se observamos quem é vitimado por essas balas, contudo, fica evidente que pouco há de aleatoriedade nesses ditos acidentes. Como pontua uma das entrevistadas Bárbara -, "a bala nunca é perdida, é achada. Sempre acha um negro, um pobre, morador de periferia". Opto, assim, pelo uso dessa expressão, mobilizada por diversos ativistas contra a violência policial.

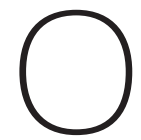

primeiro semestre de 2020 foi marcado pela pandemia do novo Coronavírus e a necessidade de isolamento social. Na contramão do que seria de se esperar, entretanto, o fato de a população estar mais recolhida em casa não impediu um aumento de $7 \%$ na letalidade da ação policial ${ }^{1}$. Pelo menos 3.148 brasileiros foram mortos em decorrência de intervenções policiais nos primeiros seis meses de 2020, 17 vítimas diárias. Esses números demonstram um crescimento em relação ao primeiro semestre de 2019, ano que, por sua vez, tinha apresentado o maior número computado pelo Fórum Brasileiro de Segurança Pública (FBSP), desde 2013, quando elas começaram a ser monitoradas. Em todo o ano de 2019 foram 6.357 mortes, sendo que três estados sozinhos corresponderam a mais da metade delas (53,4\%): Bahia, com 716 mortes; São Paulo, com 867; e Rio de Janeiro, com 1.810. Esses números, alarmantes, são seguramente defasados em relação à realidade, já que são as próprias polícias que cometem e registram os homicídios, obstruindo o caminho da denúncia.

Os alvos da letalidade da ação policial tendem a seguir um perfil: são homens (99,2\% das vítimas no primeiro semestre de 2020), jovens (73,8\% entre 15 e 29 anos) e negros (79,1\%). Contudo, casos como o das meninas Rebeca Beatriz e Emily Victoria, de 7 e 4 anos, atingidas por balas achadas ${ }^{2}$ da polícia militar enquanto brincavam na porta de casa, em uma comunidade de Duque de Caxias (RJ), em dezembro de 2020, demonstram que nenhum morador de periferias e favelas está salvaguardado no Brasil atual. Nesses locais, em que o Estado é na maior parte do tempo ausente, quando aparece, mostra-se em sua face mais violenta.

Ao passo em que aumentam as vítimas da violência institucional, aumentam também as famílias em luto e a quantidade de mães ultrajadas (Rocha, 2014). Segundo Luciane de Oliveira Rocha, a partir do luto provocado pela ação violadora dos agentes de segurança do Estado e das emoções de ultraje atreladas a ela, forja-se uma força entre essas mulheres. Força essa que resulta em ação política, identificação enquanto coletivo e poder para resistir à opressão. A partir, então, da união entre mulheres que compartilham a perda e o sentimento de ultraje tem se fortalecido em uma rede nacional de mães de vítimas da letalidade da ação policial nas periferias e favelas brasileiras. Para além das dores, elas compartilham uma potência política que vem se expressando em um tipo específico de ativismo político.

Com este artigo, proponho abordar o ativismo de mães ultrajadas e politicamente organizadas a partir da perspectiva dos movimentos sociais, destacando os aspectos definidores dessa ação coletiva que as aproximam de categorias frequentemen- 
te destacadas na teoria dos movimentos sociais. Saliento, ainda, a relevância de considerar as emoções em análises de ações coletivas. Sem especial atenção às emoções, seria impossível compreender em profundidade o movimento de mães, fundamentalmente constituído de afetos.

Assim como a letalidade da ação policial, o movimento de mães espalha-se por periferias e favelas de grandes cidades de todo o país. Os achados aqui examinados, contudo, resultam de uma pesquisa de mestrado desenvolvida na cidade do Rio de Janeiro (RJ) e na região da Baixada Santista (SP) (Quintela, 2017). Para a pesquisa foram realizadas entrevistas de profundidade com 12 participantes do movimento ${ }^{3}$; análise de publicações nas redes sociais dos coletivos locais que elas constituem; de documentos enviados a autoridades; bem como de matérias jornalísticas. Ademais, constam deste artigo apreciações feitas a partir da participação da pesquisadora em ações apoiadas e/ou organizadas pela rede de mães contra a violência policial, experiências que possibilitaram a observação direta das ativistas em ação.

Este artigo foi dividido em três seções, além desta introdução e das considerações finais. Na primeira, apresento o movimento de mães, comento suas origens e começo a apresentar sua caracterização. Na seção seguinte, analiso especificamente o movimento com base em categorias comumente empregadas pelas teorias dos movimentos sociais, especialmente em Charles Tilly, mas também em Sidney Tarrow, Alberto Melucci e James Jasper, dentre outros. Na terceira seção, detenho-me sobre um aspecto fundamental para esta análise: a centralidade das emoções no movimento de mães contra a violência policial.

\section{"Do luto à luta":}

\section{o ativismo de mães contra a violência policial}

\section{Primeiros passos}

Pelo que indicam as ativistas entrevistadas e as fontes secundárias, no Brasil ${ }^{4}$, o movimento de mães surgiu a partir das "Mães de Acari". O grupo, que após constantes ameaças e o assassinato de uma integrante não está mais ativo, formou-se em 1990, no Rio de Janeiro, após o desaparecimento de onze jovens moradores da favela de Acari que viajavam em grupo ${ }^{5}$. Diante da ineficiência da polícia em solucionar o caso e certas do envolvimento de agentes de segurança estatal no mesmo, as mães de alguns dos desaparecidos se organizaram para investigar o crime por conta própria e exigir respostas das autoridades. Passados 28 anos, o paradeiro dos jovens segue desconhecido, mas suas mães inspiraram outras mães por todo o país.
3. O perfil das entrevistadas é descrito no Quadro 1. Nomes aleatórios foram conferidos para cada uma. Apesar de ter recebido autorização para usar seus verdadeiros nomes à época da pesquisa, pelo tempo decorrido desde então, opto por preservá-los neste artigo.

4. A América Latina conta com uma longa tradição de movimentos de mulheres contra a violência estatal, com a marca central da mobilização da condição de mães. O de maior notoriedade, as Madres de la Plaza de Mayo, surgiu em 1977, em oposição aos "desaparecimentos forçados" de civis durante a Ditadura Militar Argentina (1976-1983). As Madres argentinas introduziram formas de ação coletiva que se tornaram características de movimentos de mães no mundo todo, inspirando, ate mesmo, a atuação de mulheres contra a ditadura no Brasi (Alvarez, 1990). Diversos aspectos do movimento em foco guardam semelhança com essa tradição. O grande diferencial das mães brasileiras contra a violência policial, contudo, é sua marcação de classe e raça. Conforme ficará evidente no decorrer da análise, para 
além do gênero, a negritude e a pobreza pautam a vida dessas mulheres, suas experiências, e, em decorrência, a construção de sua ação coletiva e agenda política. Assim como existe um recorte que caracteriza a violência policial, esse movimento de mães é demarcado pela posição social de suas participantes.

5, O desaparecimento dos jovens de Acari, junto com a Chacina da Candelária e de Vigário Geral (ambas em 1993), foi um dos primeiros casos a dar visibilidade ao quadro de violência da ação policial carioca, marcada desde então pela alta letalidade (Araújo, 2007).

\section{A sucessão} de assassinatos ocorridos na região entre 12 e 16 de maio de 2006, teria sido uma reação à ofensiva de membros da facção criminosa PCC contra as forças de segurança pública paulista. No decorrer de cinco dias, 505 civis e 59 agentes públicos foram mortos, apenas 6\% dos civis mortos tinham antecedente criminal (Laboratório de Análise da Violência, 2008). A maioria dos casos tem traços de execução sumária e indícios de ter sido cometida por grupos de extermínio e
Embora essa tenha sido a primeira mobilização de mães em torno dessa questão, constatou-se com a pesquisa que o movimento de mães, no molde atual, começa a se forjar efetivamente em 2006, a partir da formação do "Movimento Independente Mães de Maio", na Baixada Santista. O Mães de Maio brasileiro surgiu após uma onda de assassinatos no estado de São Paulo, posteriormente conhecida como

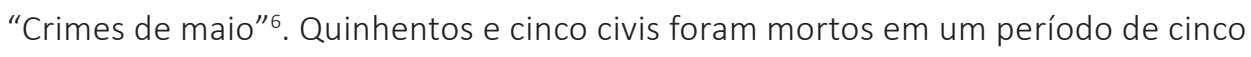
dias, ninguém foi preso. Diante da falta de respostas - de forma semelhante a como se havia dado com as Mães de Acari -, o Mães de Maio tem início com a união de mães de vítimas com o propósito de exigirem, juntas, a devida investigação e punição dos envolvidos. Pouco a pouco, elas formaram uma rede local, com mães de vítimas dos crimes de maio e de outros crimes cometidos por policiais. Com o tempo, e a notoriedade adquirida, o movimento ganhou caráter nacional, sendo constituído de mães de vítimas por todos o país.

Ainda hoje, a forma mais comum de o movimento de mães atrair novas participantes é uma ativista tomar conhecimento de uma execução policial e contatar a mãe da vítima. No primeiro momento, as mães mais antigas compartilham seus conhecimentos sobre como proceder judicialmente e oferecem apoio emocional e, então, apresentam os objetivos e ações do movimento, convidando a mãe a engrossar a luta pública. Além do convite direto, algumas mães tomam conhecimento do movimento na própria comunidade, ou pela mídia, ou por intermédio de ativistas e movimentos sociais relacionados à causa dos direitos humanos.

A partir de 2006, as integrantes do Mães de Maio começaram a viajar o país denunciando a grave violação aos direitos humanos representada pela chacina paulista e pressionando o poder público, primeiro estadual e depois federal, por respostas. No decorrer desse processo, elas ganharam notoriedade e estabeleceram contato com apoiadores e ativistas de outras causas sociais. Pelo que pude constatar, foi depois de ganhar projeção nacional que o Mães de Maio passou a ser procurado por mães de outras regiões e a inspirar a formação de grupos locais de mães ${ }^{7}$ contra a letalidade da ação policial.

Concomitantemente ao progressivo aumento da letalidade da ação das polícias brasileiras, a atuação das Mães de Maio foi se fortalecendo e os coletivos locais se multiplicando, dando vida a um movimento social que extrapola as fronteiras regionais. Embora a existência de grupos locais resulte, eventualmente, em divergências internas, quando ocupam a arena pública, essas mulheres se colocam como um ator coletivo unificado, compartilhando um repertório de ações, entoando uma identidade comum e defendendo o mesmo projeto político. Por isso, acredito ser possível fazer considerações do movimento mais amplo a partir das 
observações feitas na cidade do Rio de Janeiro (RJ) e em Santos (SP), onde estive entre julho e agosto de 2017, com o apoio de uma bolsa de intercâmbio acadêmico do Procad/Capes e do Instituto de Ciência Política da Universidade de Brasília (Ipol/UnB).

Foram entrevistadas 12 ativistas, entre integrantes do Mães de Maio residentes da região metropolitana da Baixada Santista (SP), e integrantes de coletivos locais cariocas (como o Mães de Manguinhos) ${ }^{8}$, além de mulheres que se alinhavam individualmente à pauta das mães contra a violência policial, ou que compunham a Rede de Comunidades e os Movimentos Contra a Violência (Rede) ${ }^{9}$, também no Rio de Janeiro.

O primeiro contato com as integrantes dos movimentos deu-se através das páginas do Mães de Maio e do Mães de Manguinhos no Facebook. O primeiro grupo foi selecionado justamente por sua notoriedade, ao passo que tomei conhecimento do segundo por meio de matéria jornalística que relatava um protesto das mães de vítimas de violência policial. A partir do contato virtual, foram selecionadas as primeiras entrevistadas, Bárbara e Angela, duas das fundadoras dos respectivos movimentos e as gerenciadoras de cada página no site. As demais entrevistadas foram indicadas pelas duas e por Denise, da Rede, a quem conheci através da Angela. As três intermediaram todos os demais encontros, os quais ocorreram na casa das entrevistadas, no escritório da Rede, no Centro do Rio de Janeiro, ou em estabelecimentos comerciais, conforme o desejo de cada uma.

\section{Características do ativismo}

A especificidade mais evidente do movimento em análise é precisamente a condição de mãe de suas integrantes. A luta contra as violações cometidas por agentes de segurança estatal nas periferias é marcada por um forte recorte de gênero, são raríssimos os casos de homens ativos nessa batalha. Uma das razões que podem explicar esse protagonismo feminino é a ainda manifesta divisão sexual do trabalho ${ }^{10}$, a qual responsabiliza prioritariamente as mulheres pelos cuidados com os filhos, enquanto desobriga os homens. Denise afirmou que "normalmente quem entra na luta é a mãe", justamente porque "o pai trabalha" e "alguém tem que botar comida dentro de casa". Divide-se assim "porque a mãe foi quem gerou e colocou no mundo. Eu me sinto responsável pela vida do meu filho".

Ficou evidente durante a pesquisa que as ativistas compartilham esse entendimento de que, enquanto mães, eram as principais responsáveis pelos filhos. Por isso, a luta por justiça em relação às suas mortes é interpretada como ato de amor, mas agentes do Estado (International Human Rights Clinic \& Justiça Global, 2011).

7. A especificação se faz necessária pois diversos grupos organizados contra a violência policial, sem a demarcação da maternidade, são anteriores ao das Mães de Maio - a exemplo da própria Rede, citada na sequência. Fundada pela irmã de um sobrevivente da Chacina da Candelária, em 1993, a Rede resulta da junção de movimentos que atuavam nessa pauta desde a chacina, apresentando-se como representante de comunidades movimentos e familiares, em geral.

8. O Mães de Manguinhos foi constituído entre o fim de 2014 e o início de 2015, por duas mães cujos filhos foram mortos por policiais na favela onde nasceram e foram criados Manguinhos. Hoje, o grupo conta com a participação de algumas outras mães de vítimas na mesma comunidade e com o apoio do Fórum Social de Manguinhos, da Rede, da Anistia Internacional e da Justiça Global.

9. Formada em 2004, em resposta a repetidas chacinas que ocorriam no Rio de Janeiro, a Rede é o grupo de maior visibilidade 
entre os que lutam contra a violência estatal na cidade, sendo composta por familiares de vítimas da brutalidade policial (predominantemente, mas não exclusivamente, mães).

10. A divisão sexual do trabalho é caracterizada pela designação prioritária dos homens à esfera produtiva e das mulheres à esfera reprodutiva, dos trabalhos domésticos. Ainda hoje, as mulheres brasileiras são desproporcionalmente encarregadas pela casa e pelos cuidados. Segundo a Pesquisa Nacional por Amostra de Domicílio (Pnad) de 2015 (IBGE, 2016), entre a população brasileira maior de 16 anos, 52,6\% dos homens afirmam se ocupar de tarefas domésticas, contra $89,9 \%$ das mulheres. Enquanto eles, em média, dedicam 10,8 horas por semana a essas atividades, as mulheres dedicam mais que o dobro: 24,4 horas.

11. Como exemplos, temos a esterilização forçada como prática amplamente utilizada no Brasil nos anos 1990, principalmente na região Nordeste, com o intuito de controlar o aumento da população negra e pobre (Reichmann, 2010); e a defesa da legalização do aborto como instrumento também como prolongamento de suas obrigações maternas. Nesse sentido, muitas vezes o engajamento político aparece em falas como sendo menos uma escolha e mais um tipo de dever moral do qual elas, enquanto mães, não poderiam se esquivar. "Mãe, quando tem um filho precisando, tem que largar tudo e focar naquele filho", pontua Júlia. No momento em que os filhos são vítimas de uma injustiça, lutar contra o injusto é a forma que encontram de cuidar: "quando eu estou nos lugares falando dele é como se eu continuasse cuidando dele" atesta Angela. "Eu sempre lutei para criar meu filho, não é porque ele morreu que minha luta acabou", Fernanda pontua.

A maternidade é, portanto, a grande propulsora desse ativismo, os sentidos atrelados a ela forjam a motivação primordial. Mas cumpre também um importante propósito de estratégia política para o movimento, em uma sociedade que "valoriza as mães quase à exclusão de todas as outras mulheres" (Taylor, 2001: 106). Ao participar de ações e conversando com integrantes, ficou evidente como a condição de mães é constantemente reforçada, na mesma medida em que é salientada a questão da dor e do luto impostos a elas pelo Estado. Em semelhança a outros movimentos de mães latino-americanos, ao reforçarem sua associação ao papel social a partir do qual a sociedade ainda atribui as virtudes femininas, essas muIheres obrigam essa mesma sociedade a reconhecer sua causa. Com isso, elas não garantem, necessariamente, apoio, mas, no mínimo, que admitam a legitimidade da mobilização (posição similar é encontrada em Bila Sorj (2016). Afinal, a luta das mães representaria, em última instância, o cumprimento de seu papel social, do cuidado, mesmo em meio às maiores adversidades.

Importa salientar que as mulheres de quem estamos falando são, em sua maioria, negras e, em sua totalidade, moradoras de bairros populares e periféricos. Nesse sentido, elas não correspondem à figura de mulher atrelada ao ideal (burguês) de maternidade, frágil e vulnerável, dedicada exclusivamente à vida doméstica. São mulheres que, pressionadas pelas necessidades socioeconômicas, desde sempre se dividiram entre o cuidado dos filhos e o trabalho "produtivo". Não por isso, elas são menos pressionadas por esse ideal de maternidade. Em verdade, podemos considerar que salientar a maternidade e um amor materno incondicional é um quê de resistência frente a um sistema que não apenas dificulta o exercício de sua maternidade, mas, frequentemente, as trata como mães indesejáveis ${ }^{11}$.

Concomitantemente à demarcação da condição de mães, as ativistas se definem em oposição ao Estado, o responsável por sua dor e, consequentemente, por incitar seu engajamento. Segundo Rocha (2014), a virtuosidade das "mães" é contrastada à infâmia do Estado, quando esse assume uma posição violadora. Assim, 
QUADRO 1

PERFIL DAS ENTREVISTADAS

\begin{tabular}{|c|c|c|c|c|c|c|}
\hline Nome & $\begin{array}{l}\text { Local de } \\
\text { residência }\end{array}$ & $\begin{array}{l}\text { Situação } \\
\text { conjugal }\end{array}$ & Raça & Escolaridade & Ocupação & $\begin{array}{c}\text { Parentesco, } \\
\text { gênero e idade } \\
\text { da vítima }\end{array}$ \\
\hline Angela & Manguinhos, RJ & Relação estável & Negra & Ensino superior & $\begin{array}{l}\text { Pedagoga } \\
\text { (inativa) }\end{array}$ & Filho, 19 anos \\
\hline Bárbara & Santos, SP & Viúva* & Negra & $\begin{array}{c}\text { Ensino } \\
\text { fundamental }\end{array}$ & Dona de casa & Filho, 29 anos \\
\hline Carla & Santos, SP & Viúva* & Negra & Ensino médio & Faxineira & $\begin{array}{l}\text { Irmão**, } 18 \\
\text { anos }\end{array}$ \\
\hline Denise & $\begin{array}{l}\text { Morro do } \\
\text { Borel, RJ }\end{array}$ & Casada & Negra & $\begin{array}{l}\text { Ensino médio } \\
\text { incompleto }\end{array}$ & $\begin{array}{c}\text { Operária } \\
\text { aposentada }\end{array}$ & Filho, 19 anos \\
\hline Elaine & Santos, SP & Separada & Branca & Não estudou & Diarista & Filho, 30 anos \\
\hline Fernanda & Manguinhos, RJ & Separada & Negra & $\begin{array}{c}\text { Ensino } \\
\text { fundamental } \\
\text { incompleto }\end{array}$ & $\begin{array}{l}\text { Vendedora } \\
\text { ambulante }\end{array}$ & Filho, 18 anos \\
\hline Giovana & Rocinha, RJ & Separada & Branca & $\begin{array}{c}\text { Ensino } \\
\text { fundamental } \\
\text { incompleto }\end{array}$ & $\begin{array}{c}\text { Empregada } \\
\text { doméstica } \\
\text { inativa }\end{array}$ & Filho, 33 anos \\
\hline Heloísa & $\begin{array}{l}\text { Complexo do } \\
\text { Chapadão, RJ }\end{array}$ & Separada & Negra & $\begin{array}{l}\text { Ensino } \\
\text { fundamental } \\
\text { incompleto }\end{array}$ & Faxineira & Filho, 17 anos \\
\hline Isabela & Guarujá, SP & Separada & Branca & $\begin{array}{c}\text { Ensino } \\
\text { fundamental } \\
\text { incompleto }\end{array}$ & Desempregada & Filho, 28 anos \\
\hline Júlia & Riachuelo, RJ & Separada & Negra & $\begin{array}{l}\text { Ensino médio e } \\
\text { especialização }\end{array}$ & $\begin{array}{l}\text { Assessora } \\
\text { legislativa }\end{array}$ & Filho, 20 anos \\
\hline Lúcia & Santos, SP & Casada & Negra & $\begin{array}{c}\text { Ensino } \\
\text { fundamental } \\
\text { incompleto }\end{array}$ & Dona de casa & Filho, 25 anos \\
\hline Marília & Santos, SP & Viúva & Branca & $\begin{array}{l}\text { Ensino } \\
\text { fundamental } \\
\text { incompleto }\end{array}$ & $\begin{array}{l}\text { Manicure e } \\
\text { cabeleireira }\end{array}$ & $\begin{array}{c}\text { Filha, } 20 \text { anos, } \\
\text { e neta, sendo } \\
\text { gestada }\end{array}$ \\
\hline
\end{tabular}

* Viúvas de companheiros também mortos pela polícia.

** Criado desde cedo pela irmã e seu companheiro.

Fonte: autora. de prevenção e contenção da violência, por um governador do Rio de Janeiro, que afirmou que as mulheres das favelas cariocas eram "fábricas de produzir marginal" Disponível em: <http:// g1.globo.com/ Noticias/Politica/0, MUL155710-

5601,00-CABRAL+DE FENDE+ABORTO+CO NTRA+VIOLENCIA+N $O+R I O+D E+J A N E I R O$ html>.

essas mulheres se colocam como representantes do lado justo, como defensoras das populações vulneráveis, em oposição ao lado corrompido, justamente o que deveria protegê-las e, pelo contrário, as viola.

Para Carla, o papel do Estado brasileiro parece "fazer uma faxina geral nas periferias", "eliminar os pretos e os pobres, tirar a pedra do caminho deles" e não, por exemplo, investir na educação: "educação para eles é prejuízo, porque eles não querem pessoas politizadas, informadas de seus direitos". Fernanda concorda: "a gente mora num lugar carente, não tem apoio de ninguém. E quem poderia dar uma ajuda para nós, que é o Estado, só vem para trazer tristeza para dentro da favela". Na mesma linha, Denise assinala que, embora toda criança nasça com direitos, "nas comunidades eles são todos violados". Diante desse cenário, as mães se veem na urgência de se organizar politicamente para efetivar as garantias que deveriam, em 
12. As ativistas entendem que o problema não se resume ao policial que comete o crime, mas abrange todo o sistema por trás - o Estado - que chancela a sua ação, a estimula e a protege. Conforme Angela, "é o agente que aperta o gatilho, mas é o Estado quem mata, porque ele permite. Então, ele tem que ser cobrado sim". Reforça essa compreensão o fato de que a maioria dos casos desse tipo sequer é investigado, sendo arquivada com a justificativa de que as vítimas morreram em confronto com a polícia, configurando auto de resistência. Nos raros casos em que há julgamento, o policial infrator dificilmente é condenado. teoria, estar dadas de antemão: "é direito meu ter um Estado brasileiro que me dê condições para viver nele e quem garante isso sou eu mesma, obrigando ele a me proporcionar os meus direitos", completa Júlia.

Como aprofundaremos na próxima seção, é comum ouvir as ativistas falando a partir de um "nós", que faz política contra "eles" (Estado). Adriana Vianna e Juliana Farias (2011) identificam que o antagonismo entre "mães" e "Estado" é simbolizado em duas acusações: a de que o Estado é o responsável direto pelas mortes dos filhos $^{12}$ e a de que ele é indiferente em relação aos casos, não se empenhando na elucidação dos crimes, nem na punição dos envolvidos. Como pontua Carla, "se matam um policial eles descobrem muito rápido quem foi. Se tem vandalismo em um órgão público também, e prendem o responsável. Um homicídio da gente, não". Para Marília, a rapidez com que descobrem o assassino de um rico é contrastada ao assassinato de um pobre: "se matam um pobre, é menos um, é só número".

O movimento de mães reivindica que cada crime infligido por policiais seja investigado e que seus responsáveis sejam devidamente punidos; que as famílias das vítimas sejam reparadas (com apoio jurídico, psicológico e financeiro) e que, claro, haja o fim da violência policial. Não obstante, como evidenciado nas falas acima, as ativistas denunciam a seletividade da Justiça e do Estado brasileiro, os quais negligenciam mães e filhos por serem pobres, moradores de bairros periféricos e, em sua grande maioria, negros. Para além de cada caso individual, a luta das mães é uma luta coletiva e política que reivindica a reforma da polícia, o fim do genocídio negro e a efetiva consolidação democrática - entendida em um aspecto mais amplo, de efetiva isonomia e garantia universal de direitos.

Em conclusão, Bárbara pondera: "se a ditadura acabou, foi para a burguesia e não para nós pretos, pobres e de periferia". Lúcia concorda: "pensam que a gente vive em uma democracia, isso é uma mentira. A gente não tem direitos". Marília complementa: "a gente não tem direito de nada, nem de ir e vir e nem de expressar o que está acontecendo".

Pelo que pude perceber, foi a partir do contato com ativistas de direitos humanos, políticos e estudiosos, que o entendimento dessas mulheres se alargou e suas reivindicações adquiriram amplitude. Como assinalado nas falas reproduzidas, elas compartilham o entendimento de o que enfrentam, por sua condição econômica e racial, é a negação de direitos básicos. De modo que, embora a bandeira mais visível do movimento continue sendo a denúncia da letalidade da ação policial, esta está relacionada a uma demanda mais ampla pelo direito a uma vida digna e à assistência pública, um Estado que não se apresente apenas em sua face violenta. 
Entre as ações desenvolvidas pelo movimento de mães, constam algumas direcionadas aos indivíduos atingidos pelas violações, como o encaminhamento jurídico das famílias das vítimas, o acompanhamento psicológico das mesmas, auxílio financeiro e com cuidados domésticos, quando é o caso. Outras ações são voltadas à rede de militantes e aos apoiadores do movimento: as mães organizam e participam de debates, seminários e encontros que questionam a violência do Estado contra as populações periféricas, promovem reuniões entre elas e fazem homenagens às vítimas.

Em termos de ações públicas, algumas atividades têm como propósito denunciar a alta letalidade da ação policial e são direcionadas a órgãos e entidades no Brasil e no exterior. Por fim, as ações de confronto com o Estado propriamente ditas, que incluem, entre outras, a organização e a participação em protestos contra a impunidade policial, a seletividade da Justiça brasileira, o genocídio do povo negro e a desigualdade social. A criação de campanhas com tais bandeiras e o acompanhamento dos julgamentos dos casos das vítimas de violência policial reúnem as militantes que passam a exercer pressão sobre as autoridades através de suas manifestações.

Para reforçar o que já foi assinalado, embora, em um primeiro momento, a motivação das ativistas ao integrar o movimento seja de natureza individual (exigir reparação pela morte de seus filhos), é comum que, após o contato com a rede de mães, haja um processo de tomada de consciência, de que o problema com o qual elas lidam adquira bases estruturais. De modo que essas mulheres nunca param de exigir justiça para os seus, mas sua luta não se encerra mais nisso. Em certa medida, a Justiça para uma passa a depender da Justiça para todos. Nesse sentido, não se limita apenas a uma justiça de ordem jurídica, mas adquire forma de justiça social.

O relato de Júlia traduz essa transformação de perspectiva. Conforme conta, ela "acordou para a luta" ao perceber que a injustiça contra a qual se opunha não recaia apenas sobre o seu filho, não era "só no seu umbigo". "Hoje eu entendo que o que aconteceu não foi uma coisa para a Júlia, a situação é ampla, é mundial", afirma. Angela reforça esse entendimento ao relatar que foi a partir do contato com o movimento que percebeu "que não é qualquer pessoa que está morrendo", "que há um racismo institucional que pauta a política de segurança pública", de modo que "nenhuma mulher preta e favelada, pobre, está livre de passar pela injustiça que é ter um filho assassinado". Sendo o problema estrutural, é necessária uma mudança também estrutural, o que, claro, exige muito dessas mães. "Meu filho morreu, mas eu preciso continuar na luta porque tenho outros filhos, tenho amigos e sobrinhos. E o que aconteceu com meu filho, não quero que aconteça mais"; "não é porque 
morreu que acabou, não acabou não, nossa luta está apenas começando..." declara Fernanda.

Entre as conquistas do movimento de mães, podemos citar as esporádicas vitórias judiciais (as quais são interpretadas pelas militantes como vitórias coletivas), a criação da Semana Estadual das Pessoas Vítimas de Violências em São Paulo (Lei 15.501/2014) e no Rio de Janeiro (Lei 7637/ 2017). Por outro lado, desde a eleição do presidente Jair Bolsonaro (sem partido), elas veem cada vez mais distante uma de suas principais demandas: o fim do auto de resistência. Com efeito, o presidente é um opositor declarado de tudo o que elas defendem e um entusiasta de tudo o que denunciam.

É importante relembrar que o atual governo tentou legalizar a impunidade policial, por meio da regulamentação do que ficou conhecido como "excludente de ilicitude". No PL 882/19, proposto pelo Executivo (através do ex-ministro da justiça Sérgio Moro), propôs-se ampliar o entendimento de "legítima defesa", ao apensar ao Código Penal inciso a permitir ao juiz reduzir ou deixar de aplicar a pena a agente cujo "excesso" decorresse de "escusável medo, surpresa ou violenta emoção". Ou seja, seria uma espécie de carta branca para a execução de civis. Em meio a muita oposição, o inciso foi rejeitado.

\section{Um movimento social de mães}

Ao observar os trabalhos de Tarrow (2009), Melucci (1989) salienta a dificuldade em delimitar o campo dos movimentos sociais e em definir um movimento conceitualmente, isso em decorrência da multiplicidade de abordagens existentes. Diferentes autores tentam isolar diferentes aspectos empíricos de fenômenos coletivos para construir suas definições, de modo que, ao final, essas elucidações mais expressam uma natureza empírica do que constituem conceitos analíticos. Por não haver consenso acerca do que precisamente definiria um movimento social enquanto tal, verificar se um tipo de ação coletiva pode ou não ser assim classificado torna-se tarefa complexa.

Ainda assim, existem algumas categorias que são mais frequentemente mobilizadas na análise de ações coletivas a partir da abordagem dos movimentos sociais. De acordo com Rebecca Abers e Marisa von Bülow (2011: 53), nas últimas décadas firmou-se o entendimento de que movimentos sociais são "uma forma de ação coletiva sustentada, a partir da qual atores que compartilham identidades ou solidariedades enfrentam estruturas sociais ou práticas culturais dominantes". Essa compreensão parece ser compartilhada por teóricos que se alinham a diferentes 
linhas de interpretação, desde a corrente dos Novos Movimentos Sociais, como Melucci (1988), quanto os que seguem a Teoria do Processo Político, a exemplo de Tilly (2010) e Tarrow (2009).

Ao partir do entendimento de que não existem modelos analíticos definitivos, exponho nesta seção apontamentos teóricos com base nos quais acredito ser possível definir empírica e teoricamente o movimento nacional de mães como movimento social. Neste empenho, tomo Tilly $(1995 ; 2010)$ como ponto de partida, pela proeminência do autor na área e pela relevância de suas categorias à análise do objeto de estudo. De modo a alcançarmos uma perspectiva mais abrangente, complemento a sua abordagem com a de outros estudiosos do tema.

Segundo Tilly (2010), um movimento social se constitui da síntese de três elementos, os quais devem interagir entre si: campanha, repertório de ação coletiva e demonstrações públicas de valor, unidade, números e comprometimento (Vunc) referentes à causa. Por campanha entende-se "o esforço público sustentado de elaboração de reivindicações coletivas direcionadas a determinadas autoridades" (Tilly, 2010: 136); e sustentado porque não se trata de um evento único - são esforços persistentes, como define Jasper (2016). Já o repertório de ação coletiva, diz respeito ao emprego de combinações de formas específicas de ação política, de uma rotina de ações - integradas ao todo ou em partes às campanhas sustentadas. Deixemos para comentar demonstrações de Vunc mais adiante, junto à análise do movimento de mães.

Ao observar as mães contra a violência policial, identificamos a existência interativa desses três elementos em sua ação coletiva. Conforme relataram as participantes entrevistadas, suas ações estão longe de constituir um evento único, é um trabalho continuo que já leva anos (para algumas, mais de uma década), configurando uma campanha sustentada de reivindicações coletivas. As ativistas tentam organizar encontros nacionais anuais com mães de diferentes regiões, mas, independentemente disso, ao menos no Rio de Janeiro e na Baixada Santista, as manifestações e reuniões com os grupos locais são constantes - por vezes, contando com a participação de ativistas de outras cidades - e sempre compartilhadas com toda a rede.

Dentre as ações que consegui acompanhar durante a realização da pesquisa, houve a Semana do Julho Negro ${ }^{13}$, quando ativistas de São Paulo estiveram na cidade. É necessário notar, contudo, que a realidade material dessas mulheres se impõe, tornando difícil encontros presenciais entre residentes de localidades diferentes. Não obstante, foram frequentes os relatos de conversas on-line entre as mães entrevistadas, moradoras da região Sudeste, com mães do Nordeste e do Centro-Oeste.
13. O Julho Negro consiste em um conjunto de ações de debate e protesto realizadas no Rio de Janeiro, no período de uma semana, cujo intuito é chamar atenção para questões como o genocídio do povo negro, o racismo e a violência policial. Protagonizado pelos movimentos de mães e de familiares de vítimas do Estado brasileiro, Julho Negro conta com o apoio e a adesão de diversos grupos que atuam em prol dos direitos humanos e contra a violência estatal. Dentre esses, em 2017 participaram mães e familiares de desaparecidos, de vítimas da violência Estatal da Palestina e do México, representantes do Black Lives Matter e da Associação de Haitianos do Brasil. 
14. Entre as 12 entrevistadas, o caso do filho de Heloísa era o único que ainda estava em andamento.
Com efeito, a internet cumpre uma função fundamental de facilitação do estabelecimento e da manutenção da rede entre as mães. Giovana conta: "quando eu estou muito mal, eu vou na internet e desabafo. Aí vem a Angela, as outras mães. 'Sente meu abraço, não fica assim', e é isso que vai me dando forças para não desanimar". Mais adiante, comentaremos o papel imprescindível do apoio emocional que as mães compartilham.

A campanha do movimento de mães é composta, portanto, por atos frequentes, que incluem atividades de denúncia da violência policial, do genocídio do povo negro e de violações de direitos humanos, além de eventos em homenagem às vítimas, as quais são lembradas nominalmente em todos os atos dos quais as mães participam. Ademais, as mães organizam protestos quando há uma execução policial nas comunidades, ou julgamento de policiais envolvidos em homicídios. Elas costumam comparecer em peso nessas audiências, simultaneamente, protestando contra o Estado e prestando apoio à família da vítima. Heloísa relata como foi no julgamento do executor de seu filho ${ }^{14}$, dia que também marcou sua adesão ao movimento: "eu fui para o fórum, e eu vi aquelas mulheres com os cartazes na mão e pensei 'ué, isso é para mim?'. Na hora me enturmei com aquelas mães, desabafei... REDE!! Ali que eu me fortaleci, que eu me encontrei, porque até então eu pensava que estava sozinha".

Tilly (2010) enumera três elementos como constituintes de uma campanha: um grupo de demandantes autodesignados, um/uns alvo/s de demanda e um público. Todos os três podem ser verificados no movimento de mães: elas são, evidentemente, o grupo de demandantes e o Estado é, simultaneamente, o algoz denunciado e o alvo de sua demanda - a quem cabe proporcionar reparação em relação aos crimes cometidos e ao combate da violência indevida de seus agentes. Como observado na seção anterior, o Estado é alvo também de reivindicações mais amplas de acesso a direitos básicos que lhes são frequentemente negados, como o tratamento isonômico, o direito de ir e vir e o próprio direito à vida. Já o público das campanhas é a sociedade civil. Com as campanhas, além de pressionar as autoridades, as mães buscam chamar atenção da população para a causa e atrair novos apoiadores. Para tanto, por vezes, as ações organizadas interferem no curso usual da rotina de muitas pessoas - elas ocupam avenidas, ou protestam em frente de órgãos públicos, por exemplo.

Evidentemente os tipos de ação executados pelas mães resultam de escolhas, as quais são pensadas como as formas mais adequadas de se fazer reivindicações direcionadas ao Estado, enquanto chamam atenção da sociedade e da mídia para a causa, como comentado por Tarrow (2009). Fica evidente também que elas apre- 
sentam um repertório específico de ações coletivas, o qual se constitui de formas consagradas, mas também particulares de ações de protesto. Saliento, nesse sentido, a capacidade criativa do movimento, característica de um movimento social ressaltada por Tilly (2010), além de Jasper (2016) e Melucci (1989).

No decorrer do próprio engajamento, as mães aprendem quais são as formas de mobilização mais e menos efetivas, assim como as aprimoram e transmitem seus conhecimentos para as novas integrantes. Consoante o relatado pelas participantes e trabalhos como o de Vianna e Farias (2011), esse movimento constitui também um espaço de aprendizagem. Através da participação no mesmo, da comunicação entre ativistas e com outros movimentos sociais, as mães aprendem como se posicionar na arena pública, quem contatar em cada ocasião, a quem reclamar o quê e a quem direcionar cada ação. Nesse processo, elas constituem e aperfeiçoam seu repertório, em constante transformação.

O relato de Bárbara é bastante representativo desse processo de aprendizagem. "A única coisa que eu aprendi na minha vida foi a criar meus filhos, eu era leiga de tudo. Eu não sabia falar, nunca tinha pego nem um ônibus para subir a serra, que é a uma hora e trinta de Santos". Hoje, ela não só já falou da tribuna da Câmara dos Deputados, em Brasília, na Universidade de Oxford como, por meio das Mães de Maio, realiza "cursos de formação", criando núcleos de mães de vítimas em outras cidades. Como explica "a geografia é muito grande e a gente não pode estar em todos os lugares". Por isso, elas viajam "dizendo para elas quem a gente é, e como elas devem fazer", a intenção - salienta - é colocar "elas como protagonistas, não nós"; que elas percam o medo "para poder avançar e lutar com as próprias pernas": para que seja construída uma rede nacional.

Se, por um lado, como já assinalado, a marcação de raça e classe diferencia a agenda dessas mães da agendas das demais mulheres-mães (em geral, brancas e de classe média) que protestavam contra o desaparecimento de civis nas ditaduras latino-americanas, por exemplo; por outro, uma das especificidades do repertório de movimentos de mães, como esse, é precisamente a marcação da maternidade, que as distinguem de outros movimentos alinhados à defesa dos direitos humanos ou contra a violência policial. A rotina de ação dessas militantes é orientada por um desejo de justiça, mas, preponderantemente, pela dor, a dor materna pela perda de um filho. Como ressaltado em James Jasper (1997) e Manuel Castells (2013), a emoção é um importante motor para a mobilização social e, nesse caso, elas não apenas motivam a formação do movimento como pautam as suas ações e os seus posicionamentos - assunto a que voltaremos na próxima seção. 
Outro elemento assinalado por Tilly (2010) como definidor de movimentos sociais, são as demonstrações públicas de valor, unidade, números e comprometimento (Vunc) referentes à causa. Tilly (2010: 138) cita como exemplos de demonstração de valor "comportamento sóbrio; roupas asseadas; presença de clérigos, dignatários e mães com crianças". No caso em foco, acredito que essa se baseia precisamente na mobilização da condição da maternidade e da dor imposta às ativistas pela atitude violadora do Estado. Ou seja, o valor das demandantes é contraposto à indignidade de seu opositor.

Elaine descreve a dor imposta por seu violador, em contraste com sua dedicação ao filho: "a gente luta durante 30 anos, cuida do filho durante 30 anos, com o maior carinho. E aí, eles vêm e tiram a vida dele, a minha vida. Tiram a minha história e tudo de mim". A vida agora é lutar por justiça: "a gente vive ainda porque pede muita força para Deus. Tem que viver para continuar na luta. Mas não é mais feliz".

Para além da imagem de uma mãe valorosa - e sofredora -, ressalta-se a boa índole do filho perdido, do sujeito íntegro que foi vitimado injustamente. A necessidade de ressaltar as qualidades (trabalhador, pai dedicado, filho exemplar...) da vítima também é central a esse ativismo, pois essas mães se veem obrigadas a enfrentar o discurso, difundido pelo Estado e pela mídia, de que quem é morto pela polícia não é inocente, mas criminoso em confronto (o qual, segundo essa lógica, não seria merecedor de piedade, ou sequer de um julgamento justo). Torna-se preciso convencer nossa sociedade punitivista de que aquela é uma vida a ser defendida, que a sua supressão é inaceitável.

Vale salientar que é prevista a pena de morte no Brasil, apenas em caso de guerra. Sendo assim, independentemente de quem era a vítima e/ou de seus antecedentes, não cabe à polícia decidir quem merece ou não viver, sendo sua competência funcional apenas encaminhar suspeitos às autoridades responsáveis por seu julgamento. Infelizmente, contudo, este não é o entendimento corrente, de modo que, além de lidar com a perda, essas mulheres ainda precisam enfrentar o julgamento moral de seus filhos, como se fossem eles os réus: "você vê a vítima sendo julgada no lugar de quem está com as mãos sujas de sangue", queixa-se Angela. Muitas relataram que, após a morte, seus filhos foram mentirosamente referenciados como "criminosos" e/ ou traficantes, como se isso justificasse a execução. Por isso, uma de suas demandas é a retratação do Estado, o reconhecimento de sua culpa e da inocência das vítimas.

Ao recorrer à abordagem das molduras interpretativas da ação coletiva (Miac's) de Marcelo Hunrath Silva, Fernando Cotanda e Matheus Pereira (2017), é possível afirmar que o movimento de mães expressa uma disputa de enquadramentos interpre- 
tativos. Através da ação contestatória, as ativistas defendem um enquadramento da questão das mortes causadas por ação policial nas periferias que é alternativo (e, em certa medida, antagônico) ao defendido por autoridades e setores da mídia. Giovana define o que enfrentam: "o Estado acaba com a vida da gente e eles (policiais) que são as vítimas, não somos nós. Eles botam a gente como se fôssemos os culpados daquilo ter acontecido". Elas sabem que não é assim, e querem tornar pública essa verdade. Conforme William Gamson (1985), desenvolver e aplicar um enquadramento alternativo ao hegemônico é precisamente um requisito da contestação social.

O enquadramento proposto pelo movimento de mães busca promover o reconhecimento social da legitimidade de suas demandas e conquistar apoio para a sua causa. Com isso não procuro sugerir que essa interpretação é mero recurso estratégico, evidentemente, refletem convicções autênticas das mães. É precisamente por acreditarem no valor da vida de seus filhos e de toda a população preta e periférica que elas contestam a ação estatal.

Para retomar os demais aspectos presentes nas demonstrações de Vunc enunciados por Tilly (2010), temos o da unidade. Em relação ao movimento de mães, ressalta-se o uso de camisetas e faixas com fotos e nomes de vítimas, além de bandeiras com palavras de ordem e os nomes dos grupos locais. Assim como a realização de marchas em regiões centrais das cidades em que as mães atuam, ou nas comunidades em que houve vítimas. Nessas marchas, as militantes prestam homenagens às vítimas e contam suas histórias, pedem o fim da violência policial e a desmilitarização da polícia militar e denunciam agentes do Estado (por contravenção ou ineficiência). As demonstrações de números do movimento também se dão, sobretudo, em ações desse tipo, em que as mães e os apoiadores ocupam avenidas e a entrada principal de órgãos públicos. Já as de comprometimento se baseiam na constante evocação da dor das mães. Foi a partir da imposição externa da dor da perda que essas mulheres constituíram esse movimento e é também apesar dessa dor que elas se mantêm engajadas.

Em qualquer rápida conversa com as ativistas são enunciados os diversos obstáculos que precisam enfrentar para participar do movimento. Fernanda, por exemplo, foi uma das que desenvolveu problemas de saúde após a morte do filho; Giovana, evita sair de casa por ter sido ameaçada de morte, o que a obrigou, em consequência, a parar de trabalhar, fazendo com que dependa da ajuda de familiares e amigos; já Angela diz que se mantém engajada apesar do desencorajamento de familiares. Não obstante, todas as entrevistadas ressaltaram que se mantêm firmes na luta por acreditarem em sua causa e pelo comprometimento com as demais, como será comentado logo adiante. 
15. Durante as entrevistas, embora tenham sido frequentes os relatos das dificuldades enfrentadas pelas ativistas, a participação na rede de mães sempre foi referida por todas como fonte de força e de sustentação mútua. Talvez por isso, somado ao fato de eu ser alguém de fora, sem qualquer contato com elas anterior à pesquisa, não chegou a mim qualquer relato sobre contradições e disputas internas ao movimento. $\mathrm{O}$ que não significa, claro, que elas não existam, como em qualquer outra ação coletiva.
O forte vínculo que as mantém unidas, baseado no reconhecimento e na legitimação mútuos, contrasta com a observação de Eder Sader (1988) de que, no Brasil, frequentemente os movimentos sociais têm de construir suas identidades enquanto sujeitos políticos precisamente porque elas são ignoradas nos cenários públicos instituídos. É o caso dessas mulheres, cuja existência parece ser negligenciada pelo Estado, até que elas passem a confrontá-lo.

Tilly (2010: 149) também enuncia a reivindicação de uma identidade, a afirmação de um "nós", como força unificada a ser enfrentada como característico de movimentos sociais. Melucci (1988) ressalta ainda o caráter interativo e compartilhado da definição da identidade coletiva de um movimento, a qual não só é produzida por diversos indivíduos como se relaciona às orientações da ação e ao "campo de oportunidades e constrangimentos no qual a ação acontece" (Melucci, 1988: 342). A identidade é pensada em relação aos objetivos do movimento, no nosso exemplo, a identidade de mães ultrajadas visa conquistar atenção, transformações, reconhecimento e apoiadores para a causa.

Para Tarrow (2009: 41), "entendimentos e identidades compartilhadas", estimulariam o desenvolvimento de relações de cooperação e confiança entre os participantes de um movimento, sendo responsáveis pela adesão e manutenção da ação coletiva. Angela afirma que sente como se tivesse uma segunda família, que é a "família da luta", "quando eu estou com essas mães eu me sinto muito cuidada". E Fernanda, no mesmo sentido: "agora se tornou tudo uma família só, as Mães de Manguinhos com as Mães de Maio, as outras mães de outras favelas. Uma dando apoio à outra, dando suporte à outra para a gente poder seguir em frente".

Além do acolhimento que elas recebem e proporcionam umas às outras, a experiência dolorosa compartilhada forja uma identificação única entre elas, um tipo de entendimento que não está disponível a quem não dispõe da mesma vivência traumática. Dessa, forja-se a identidade do grupo, o companheirismo e a confiança que as mantém firmes, unidas e em movimento ${ }^{15}$. Como explica Júlia: "a família que a gente adquire por conta da dor, por conta da semelhança da violência do Estado, essa a gente se identifica, porque a dor dela é a mesma". Assim, "são pessoas com quem você não tem nenhum vínculo anterior, mas eu ter uma empatia, chorar pela dor dela, eu estar junto com ela no momento de buscar justiça, acaba sendo mais importante, muitas vezes, do que o amor que eu tenho pela minha própria família".

O último tipo de reivindicação dos movimentos sociais ressaltado por Tilly (2010: 149) é o de posição, a afirmação de laços e similaridades com outros atores políticos. Um aspecto preponderante para o movimento de mães contra a violência 
policial são, precisamente, as redes formadas com outros movimentos e organizações. Elas estão em constante comunicação e desenvolvendo ações conjuntas com movimentos em defesa dos direitos humanos, das populações periféricas e faveladas, contra o genocídio da população negra e pela reforma das polícias, entre outros; movimentos por todo Brasil, mas também em outros países, como o Black Lives Matter $(B L M)^{16}$, nos Estados Unidos.

Elas contam, ainda, com o apoio de organizações como a Anistia Internacional e a Justiça Global, as quais contribuem pontualmente com o custeio de transportes e material e promovem cursos de formação para as ativistas. O movimento também é apoiado por membros da sociedade civil não organizada, além de universidades e associações de pesquisa ${ }^{17}$, veículos da mídia alternativa, a exemplo da Ponte Jornalismo. Por outro lado, a maioria das mães entrevistadas rejeita qualquer tipo de institucionalidade e de envolvimento com a política eleitoral ${ }^{18}$. É importante, para elas, permanecerem independentes, razão pela qual, apesar das dificuldades, sustentam-se com recursos próprios - recebendo apenas contribuições pontuais.

\section{As emoções como força motriz}

Nas últimas décadas, diferentes autores vêm ressaltando a relevância de investigar as emoções como motivadoras da formação de um movimento social e do engajamento de ativistas no mesmo. Como aponta Jasper (2014), destacado autor nesta perspectiva, as emoções ajudam a explicar porque os indivíduos aderem ou abandonam um protesto e porque movimentos surgem, mas também questões menos evidentes, a exemplo da forma como decisões estratégicas são tomadas, como oponentes e autoridades reagem, os impactos dos movimentos, entre outros.

Entretanto, pesquisadores que assumem essa abordagem observam como esse ainda é um aspecto pouco explorado nos trabalhos mais hegemônicos, em detrimento daqueles considerados mais racionais. Além da minimização do papel das emoções por parte dos estudiosos, conforme Goodwin, Jasper e Poletta (2001), há uma relutância em admitir a importância das mesmas, muitas vezes, por parte dos próprios ativistas de movimentos sociais. Segundo argumentam, esse é mais um resultado do pensamento dicotômico ocidental, que realça o valor da racionalidade em detrimento da emoção.

Alguns movimentos, todavia, compreendem a relevância das emoções, tanto para recrutar novos integrantes, quanto para exercer pressão sobre os alvos de suas demandas ou chamar atenção do público sobre suas ações coletivas. É evidente o papel fundamental das emoções no movimento de mães, não apenas na motivação
16. Movimento com origem na comunidade afro-americana estadunidense, cujo objetivo é "construir poder local e intervir na violência infligida às comunidades negras pelo Estado e pelos vigilantes", segundo descrição retirada de seu site oficial: <https:// blacklivesmatter. com>. De acordo com a citada fonte, o BLM se pretende uma "rede global", de modo similar à rede de mães contra a violência policial no Brasil.

17. São citadas pelas entrevistadas a Universidade Estadual Paulista "Júlio de Mesquita Filho" (Unesp), a Universidade de Harvard, e a Latin American Studies Association (Lasa).

18. Entre as doze entrevistadas, onze expressaram rechaço e desconfiança em relação à política institucional. Apenas Júlia - que trabalhava como assessora na Assembleia Legislativa do Rio de Janeiro - destacou

a necessidade de envolver-se ativamente com a política a fim de proporcionar mudanças substanciais. Em 2020, ela se candidatou à vereadora do Rio de Janeiro; apesar de não ter sido eleita, atualmente é suplente na Câmara dos Vereadores. 
para sua formação, mas também em sua atuação e continuidade. Trata-se de um movimento formado por mulheres a quem foi imposta uma dor dilacerante, a interrupção violenta da maternidade, e que se tornaram militantes a partir do amor ao filho e da indignação que se seguiu à sua perda.

São mulheres para quem sempre foram negados acesso a direitos básicos e oportunidades, mas que, de alguma maneira, aprenderam a viver com essa negação, a se conformar com o cotidiano de negligência estatal. De um modo geral, elas não eram pessoas engajadas em lutas sociais anteriormente, mesmo vivendo a injusta realidade a que estão submetidas as populações pobres e periféricas. É, então, a partir de uma negação inaceitável - a negação do direito à vida dos filhos e de seu direito à maternidade - que elas transformam a sua raiva, dor e o ultraje em ação, dando início ao movimento social. O choque da perda do filho se transforma em raiva ativa, em identificação de um culpado (o Estado) e, então, em bases morais, em indignação (Jasper, 2014: 212).

Jeff Goodwin, James Jasper e Francesca Poletta (2001: 16) definem como "choques morais" eventos inesperados ou informações que geram uma sensação de indignação em uma pessoa que a torna inclinada à ação política. Segundo os autores, esses choques individuais representam, frequentemente, o primeiro passo para uma pessoa aderir a um movimento social. A partir do choque, percebe-se que o mundo não é como se pensava, o que exige uma reavaliação da realidade vivida (Jasper, 2014).

Além do potencial motivacional da raiva para a mobilização coletiva, Jasper alega que ela mesma permite o direcionamento da culpa para um problema social e cria simpatia entre participantes de um movimento. No caso do movimento em questão, há a identificação do Estado como infrator, como antagonista das militantes, as quais demandam a correção de sua postura, e há a criação de laços de solidariedade entre as mães de vítimas.

Ao observar o aspecto motivacional das emoções para os movimentos sociais e retomando a discussão sobre enquadramentos interpretativos levantada anteriormente, temos o conceito de "enquadramento motivacional" de Robert Benford e David Snow (2000). No caso em estudo, não é apenas a raiva que age e impulsiona mulheres que nunca se envolveram politicamente a se engajarem contra o Estado, mas a interpretação compartilhada de que seus filhos e elas mesmas foram vítimas de uma grande injustiça. O enquadramento comum que as motiva é o de que mortes como as de seus filhos são inaceitáveis, que o Estado não pode atuar dessa forma para com os seus cidadãos. Torna-se necessário, portanto, participar de um movimento capaz de exercer pressão para que não apenas casos específicos de 
violência policial sejam solucionados, mas ainda que haja a efetivação de direitos básicos para a população da qual elas fazem parte.

Além do fator motivacional, Goodwin, Jasper e Poletta (2001) ressaltam o papel das emoções no fortalecimento da identidade coletiva. Conforme apontam, um aspecto dessa identidade é o dos traços identitários propriamente ditos (como a sexualidade, a raça, ou, no caso, a condição da maternidade). Em conformidade com o que foi sustentado até aqui, Bernd Simon e Bert Klandermans (2001, apud Jasper, 2014), atestam que identidades se tornam políticas quando um inimigo externo pode ser culpabilizado por adversidades a que um grupo é submetido e a luta ocupa a arena pública. O outro lado da identidade coletiva, já apontado, é o da identidade como senso de solidariedade entre os membros de um grupo, a qual, por sua vez, é baseada em sentimentos como confiança, afeto e lealdade (Goodwin, Jasper e Poletta, 2001: 8).

Já observamos como a solidariedade de grupo ocupa um espaço central no movimento de mães. Todas as participantes são unânimes em enfatizar a forte ligação de amizade - aproximada a de um vínculo familiar - que estabeleceram umas com as outras. De modo que o "estar juntas" adquire sentido para além dos objetivos concretos do movimento, e passa a ser, em alguma medida, também um fim em si. Assim, a solidariedade explica o engajamento na ação coletiva, mas também a sua permanência. Como relata Isabela: "eu participo do movimento porque eu quero que a justiça seja feita e eu acredito que através do movimento isso pode acontecer. Mas também é uma forma de ficar bem comigo mesma. A gente adquire muita força uma com a outra, vendo outras na mesma situação".

Emoções que os ativistas de um movimento nutrem entre si são definidas por Jasper (1998) como recíprocas, mas elas não são as únicas identificadas pelo autor. Existe outro conjunto de emoções que são aquelas compartilhadas pelos membros de um grupo em respeito a objetos fora do grupo. Segundo Jasper, elas têm como consequência reforçar as emoções recíprocas, fortalecendo o sentimento de identificação e empatia mútua entre os membros de um grupo. Pensando nas mães, podemos destacar como emoções compartilhadas a indignação em relação ao Estado, o sentimento de que apenas as companheiras se compreendem verdadeiramente e a raiva direcionada a parte da sociedade, que julga essas mulheres e seus filhos como criminosos, pelo simples fato de serem pobres, negros e moradores de periferia. "O Estado mata e o preconceito absolve", resume Denise.

A formação da identidade coletiva deste grupo é também uma forma de contradizer a imagem social e midiaticamente difundida dos casos de letalidade da ação 
policial. Como apontado anteriormente, é preciso disputar o enquadramento interpretativo dessas mortes: elucidar quem é efetivamente a vítima e o culpado desses crimes. Motivo pelo qual a retratação do Estado é tão importante. "Quando eles morrem, eles são tratados como bandidos - mesmo que fosse, não tem que matar, tem que prender"; o que as mães mais querem, por isso, é que o Estado reconheça que "o policial que matou não tinha que ter feito isso", explica Denise.

É também através das emoções que manifestantes criam e sustentam um senso de obrigação moral e justiça de sua causa (Jasper, 2014). Por meio da mobilização dos afetos extremos despertados pela perda, as ativistas contra a violência policial reforçam a natureza moral e de obrigação de sua luta, caracterizando-a como luta por justiça. É ainda uma causa da qual elas não podem fugir, na medida em que o ativismo é interpretado como forma de continuar cuidando dos filhos, cumprindo suas responsabilidades maternas, traço característico do ativismo de mães (Ruddick,1989), especialmente na América Latina (Taylor, 2001).

Após anos de engajamento, as ativistas já sabem quais sentimentos e tipos de expressão são apropriados para cada cenário ou interlocutor, aspecto ressaltado por Goodwin, Jasper e Poletta (2001). Além de saber também que, às vezes, emoções não são tão bem-vindas quanto argumentos "racionais". Ao acompanhá-las em diferentes ocasiões, percebo como elas assumem posturas e discursos distintos dependendo do público. Em alguns momentos é preciso demonstrar força, enquanto em outros é possível ser mais frágil; há lugares em que se pode falar em termos de dor e outros em que deve sobressair a violação de direitos.

Um fator distintivo da forma como o movimento de mães trabalha a questão das emoções é o seu recorte de gênero. Afinal, é um estereótipo social a propensão a que as mulheres se expressem de forma mais emotiva, que sejam movidas por seus sentimentos e pautem suas ações a partir deles. Nesse sentido, há, em geral, maior aceitação a uma mulher que ressalta publicamente os seus sentimentos, em comparação a um homem. Por outro lado, a arena pública é tradicionalmente ocupada por homens e, em decorrência, um âmbito em que prevalece uma suposta racionalidade. Nesse sentido, ao se organizarem politicamente e ao ocuparem o espaço público, essas ativistas também confrontam expectativas sociais. Não apenas por ousarem mobilizar as emoções politicamente, rompendo com a pretensão dominante de racionalidade, mas também pelo próprio fato de serem mulheres e mães, trazendo ao público identidades tradicionalmente associadas à casa.

Por isso, Sara Ruddick (1989: 229) assinala que mobilizações coletivas de mães "atendem às expectativas tradicionais da feminilidade e, ao mesmo tempo, as vio- 
lam". Ainda que elas se posicionem como mães, a partir do protesto politizado essas mulheres abandonam o seu papel tradicional esperado. "Elas falam em uma 'linguagem feminina' de lealdade, amor e ultraje; mas elas falam com uma raiva pública em um lugar público de uma forma que elas nunca foram destinadas a fazer" (Ruddick, 1989: 229). Bárbara traz definição precisa nesse sentido: "a gente não luta pela paz, a gente luta por justiça para conseguir a paz".

Ou seja, o uso estratégico da condição da maternidade e das emoções atreladas a ela não significa que a ação política dessas mulheres não é de muitas formas totalmente disruptiva de papéis tradicionais de gênero. Em verdade, embora, como ressaltem, a maternidade seja um aspecto determinante de suas identidades, elas nunca foram da mesma cor ou classe do ideal de mulher-mãe descrito pelos estereótipos sociais. Toda a experiência de vida de uma mulher negra e pobre é, em si, uma resistência aos papeis convencionais de gênero.

\section{Considerações finais}

Testemunhamos um aumento na letalidade da ação policial nos últimos anos e, simultaneamente, também um crescimento no número de mulheres que se engajam politicamente contra as violações provocadas pelo Estado. Assim, é razoável prever que, não havendo uma mudança em termos de segurança pública nas grandes cidades brasileiras - e a expectativa atual é que a violência institucional só aumente -, a tendência é que o movimento de mães de vítimas de violência policial se expanda e se solidifique enquanto ação coletiva. Afinal, a cada nova vítima temos também uma nova mãe ultrajada, uma ativista em potencial.

Sustento a possibilidade de o movimento não aumentar apenas em termos numéricos, mas, cada vez mais, avançar em sua capacidade de mobilização e pressão. É fato que o movimento de mães dispõe de aspectos fundamentais para chamar atenção do alvo de suas demandas, o Estado, e da sociedade civil. Todavia, ele depende do constante aprimoramento e de consistência para se consolidar como ator político expressivo na arena pública, a exemplo de outros movimentos sociais.

Um desafio comum a movimentos sociais é conseguir construir e manter a unidade. Por ser constituído não apenas por ativistas "isoladas", mas, em grande peso, por grupos locais, com suas particularidades, evidentemente, pode haver dissonâncias e disputas internas ao movimento de mães. Entretanto, chama atenção a cooperação entre todas em torno da luta comum. A solidariedade de grupo, baseada nas relações de acolhimento e confiança que as mães estabelecem umas com as outras, é seguramente um fator central - e promissor. 
Por fim, saliento a importância de que mais análises de movimentos sociais incluam o aspecto emocional, tanto como elemento motivador para a mobilização coletiva, quanto como suporte da mesma. Sem uma perspectiva atenta a este aspecto, seria impossível captar um movimento como o de mães contra a violência policial em sua profundidade.

\section{Referências}

ABERS, Rebecca Neaera; BÜLOW, Marisa von. Movimentos sociais na teoria e na prática: como estudar o ativismo através da fronteira entre Estado e sociedade? Sociologias (impresso), v. 13, p. 52-84, 2011.

ALVAREZ, Sonia E. The politics of gender in Latin America: comparative perspectives on women in the Brazilian transition to democracy. Princeton, NJ: Princeton University Press, 1990.

ARAÚJO, Fábio A. Do luto à luta: a experiência das mães de Acari. Dissertação (Mestrado) - Instituto de Filosofia e Ciências Sociais, Universidade Federal do Rio de Janeiro, Rio de Janeiro, 2007.

BENFORD, Robert. D.; SNOW, David A. Framing processes and social movements: an overview and assessment. Annual Review of Sociology, v. 26, n. 1, p.611-639, 2000.

CASTELLS, Manuel. Redes de indignação e esperança: movimentos sociais na era da internet. Rio de Janeiro: Zahar, 2013.

FÓRUM BRASILEIRO DE SEGURANÇA PÚBLICA (FBSP). Anuário Brasileiro de Segurança Pública 2020. Ano 14. 2020. Disponível em: <https://forumseguranca.org.br/ wp-content/uploads/2020/10/anuario-14-2020-v1-final.pdf>.

GAMSON, William. Goffman's legacy to political sociology. Theory and Society, v. 14, n. 5, p.605-622, 1985.

GOODWIN, Jeff; JASPER, James M.; POLLETTA, Francesca (Eds.). Passionate politics. Emotions and social movements. Chicago, IL: University of Chicago Press, 2001.

INTERNATIONAL HUMAN RIGHTS CLINIC; JUSTIÇA GLOBAL. São Paulo sob achaque: corrupção, crime organizado e violência institucional em maio de 2006, 2011. Disponível em: <http://hrp.law.harvard.edu/wp-content/uploads/2011/05/full-with-cover.pdf>.

INSTITUTO BRASILEIRO DE GEOGRAFIA E ESTATÍsTICA (IBGE). Pesquisa Nacional por Amostra de Domicílios (Pnad), 2015. Rio de Janeiro: IBGE, 2016. 
JASPER, James. Protesto: uma introdução aos movimentos sociais. Rio de Janeiro: Zahar, 2016.

. Constructing indignation: anger dynamics in protest movements. Emotion Review, v. 6, n. 3, p. 208-213, 2014.

The art of moral protest. Culture, biography, and creativity in social movements. Chicago, IL: University of Chicago Press, 1997.

LABORATÓRIO DE ANÁLISE DA VIOLÊNCIA (LAV-UERJ). Análise dos impactos dos ataques do PCC em São Paulo em maio de 2006, 2008. Disponível em: <http://www. observatoriodeseguranca.org/files/AtaquesPCC_IgCano.pdf>.

MELUCCl, Alberto. Getting involved: identity and mobilization in social movements. International Social Movements Research, v. 1, 1988.

. Um objetivo para os movimentos sociais? Lua Nova, n. 17, Jun. 1989.

QUINTELA, Débora Françolin. Maternidade e ativismo político: a luta de mães por democracia e justiça. Dissertação (Mestrado em Ciência Política) - Universidade de Brasília, Brasília, 2017.

REICHMANN, Rebecca L. (Ed.). Race in contemporary Brazil: from indifference to inequality. Filadelfia, PA: Penn State University Press, 2010.

ROCHA. Luciane de Oliveira. Outraged mothering: black women, racial violence, and the power of emotion in Rio de Janeiro's African diaspora. Tese (Doutorado) The University of Texas at Austin, Austin, 2014.

RUDDICK, Sara. Maternal thinking: toward a politics of peace. Boston, MA: Beacon Press, 1989.

SADER, Eder. Quando novos personagens entraram em cena: experiências, falas e lutas dos trabalhadores da grande São Paulo: 1970-1980. Rio de Janeiro: Paz e Terra, 1988.

SILVA, Marcelo Kunrath; COTANDA, Fernando Coutinho; PEREIRA, Matheus Mazzilli. Interpretação e ação coletiva: o enquadramento interpretativo no estudo de movimentos sociais. Revista de Sociologia e Política, v. 25, p. 143-164, 2017.

SORJ, Bila. Políticas sociais, participação comunitária e a desprofissionalização do care. Cadernos Pagu, n. 46, p. 107-128, Campinas, Abr. 2016.

TARROW, Sidney. O poder em movimento: movimentos sociais e confronto político: movimentos sociais e confronto político. Petrópolis, RJ: Editora Vozes, 2009. 
TAYLOR, Diana. Making a spectacle: the mothers of the Plaza de Mayo. Journal of the Association for Research on Mothering, v. 3, n. 2, 2001.

TILLY, Charles. Movimentos sociais como política. Revista Brasileira de Ciência Política, n. 3, p. 133-160, Brasília, Jan.-Jul. 2010.

Contentious repertoires in Great Britain. In: MARK, T. (ed.). Repertoires and cycles of collective action. Durham: Duke University Press, 1995.

VIANNA, Adriana; FARIAS, Juliana. A guerra das mães: dor e política em situações de violência institucional. Cadernos Pagu, n. 37, p. 79-116, Campinas, Dec. 2011. 